\title{
Examining the Impact of Health Determinants on Health Outcomes in Louisiana, USA
}

\author{
Olubunmi Olanrewaju ${ }^{1}$ Elizabeth Remi Ogungbenle ${ }^{2} \quad$ Jumoke C. Adewunmi $^{3}$ \\ Southern University and A \& M College, \\ Department of Public Policy \& Urban Affairs, Baton Rouge, Louisiana, USA
}

\begin{abstract}
This study examines social health determinants that impact health outcomes for residents in Louisiana, USA. We analyze data from 2010 to 2019 County Health Rankings using the behavioral and environmental factors from the precede-proceed model framework to assess factors to consider when thinking of interventions. Results suggest that the health determinants analyzed have a great variation in the length of life and the quality of life, central domains of health outcome. This understanding of what affects population health provides valuable information to establish public health priorities and to efficiently use limited health resources. The study calls for effective training, policies and programs to raise awareness and design approaches that will potentially increase health outcomes in the state.
\end{abstract}

Keywords: Health outcomes, Health determinants, Quality of life, Length of life

DOI: $10.7176 / \mathrm{JHMN} / 68-06$

Publication date: November $30^{\text {th }} 2019$

\subsection{Introduction}

Health outcomes are very crucial to policymakers, legislators and health care practitioners across all the states in United States of America. Specifically, in Louisiana the performance of health associated with all health care programs are tied to operations and budgets. It is therefore not surprising that Armstrong (1994) argued that health outcomes reflect the performance of health and health intervention, system, or service to maintaining or increasing the wellbeing of its target population. To reiterate the significance of health outcomes to policymakers and decision makers, a study conducted by Sansoni (2016) theorized that health outcome is a measure of perceived change to the health of an individual, a group of people, or a population from a partial or complete intervention. Very importantly, it has been underscored in literature that the quality of life and length of life are central indicators of health outcomes (County Health Rankings, 2019). Perusing available literature, scholars have underscored that these two outcomes reveal the overall wellbeing of a population and they can be influenced by factors within the domain of health system as well as behavioral, economic and environmental factors not within the control of the health system (Azar et al. 2017; National Institutes of Health, 2002).

It is rather sad that despite the numerous literatures on health programs and measurement of health outcomes in the United States of America, especially in the State of Louisiana, little has been known about how certain health determinants impact on health outcomes. As part of contributing to literature and also filling in the knowledge gap, the purpose of this current study is to conduct a search, to review relevant literature and to better inform the public on how certain health determinants have impacted on health outcomes for Louisiana residents and to what extent these factors contribute to the length and the quality of their lives. Even though health inconsistencies exist as a global issue, one of the overarching goals for Healthy People 2020 is to achieve health equity, eliminate any health disparities and improve health for all people (U.S Department of Health and Human Services [DHHS], 2008). According to available literature, it is further argued that the overarching goals for Healthy People 2020 identify these disparities with social, economic and environmental disadvantage (U.S Department of Health and Human Services, 2008). Research suggests that the health inconsistencies limit overall health quality of an individual or population as well as drive up costs (LaVeist et al., 2009; Orgera \& Artiga, 2018). Therefore, an understanding of the determinants of health variations is necessary to develop new methods, strategies or interventions that will reduce or eliminate these disparities.

The U.S Department of Health and Human Services (2014) suggests that health inconsistencies which exist among population groups reflect the complex interaction among genetic variations, environmental factors and specific health behaviors but what is less clear is if these factors have significantly impacted the performance of health and health outcomes among Louisiana residents. Are the factors changing health outcomes for the better? How do we eliminate inconsistencies or constantly improve health outcomes? Consequently, the objectives of this study are first, to review factors that impact health outcome for the people of Louisiana, second to assess how these factors have influenced or continues to influence the population's health outcomes and third, to highlight the need for intervention and strategies if need be for the improvement in outcomes. The study adopted regression analysis to measure the impact of these determinants and the variation in annual trends. Data used in this study was from County Health Rankings \& Roadmaps. It is expected that this study will form a basis for the improvement of health services aimed at promoting quality health and prolonging life among Louisiana population. This paper 
can help to inform the Louisiana Department of health, the local and the state government officials about where necessary modifications to health factors are needed and about areas where they can adapt public health interventions for a firm, enduring commitment not just in community intervention but also in basic health education.

In the next section, we present a review of literature, the data and methodology employed in this study, followed by the main findings and a discussion of our results. In the final section, the concluding remarks of the study as well as the interventions to overcome health disparities are discussed.

\subsection{Literature Review}

According to the U.S Department of Health and Human Services (2008), health determinants are factors that determine the health outcomes of an individual or a population. McGraw-Hill Concise Dictionary of Modern Medicine (2002) also defines health outcome as 'the result of a medical condition that directly affects the length or quality of a person's life'. The health determinants discussed in this study are Health behavior, Social and economic environment and Physical environment.

Health Behavior factors include tobacco use, alcohol and drug use, diet and exercise. Tobacco consumption, alcohol consumption, food supply and consumption, and body weight are recognized as non-medical determinants of health (Organization for Economic Co-operation and Development [OECD], 2019). Alcohol, illicit drugs and tobacco are huge causes of ill health and premature death (Wilkinson \& Marmont, 2003). Good and adequate supply of food promotes health and wellbeing. Regular exercise is good for the body and it has been associated with better health outcomes (Elavsky et al. 2005; Mcllhenny, 2019).

Social and economic environmental factors impact health outcomes (Baffour, 2017). These factors are measured by educational attainment, employment, income, family and social support, and community safety (County Health Rankings, 2019). Lower educational level lessens the quality of life (Raggi et al., 2016). Unemployment increases health risks and shortens life (Wilkinson \& Marmont, 2003). Recent attention to social determinants of health such as education, economic stability, community safety, and availability of adequate housing has shown that they correlate with healthier populations (Office of Disease Prevention and Health Promotion, 2017). Physical environment factors include air and water quality as well as access to recreational facilities. It also includes transportation, housing, walkability and safety. Physical environment and neighborhood play a critical role in the health of individuals or communities. Reducing inequalities in the physical environment can improve health behaviors and other determinants of health, thereby helping to meet better health outcomes (DHHS, 2008).

In this study, we use the PRECEDE-PROCEED model framework to evaluate the relationship between health determinants and health outcomes. The precede-proceed framework is a comprehensive model that provides a structure for identifying health determinants, for accessing health outcomes, and for developing and implementing interventions to improve health. The model posits that PRECEDE stands for predisposing, reinforcing and enabling factors while the PROCEED refers to policy, regulatory and organizational constructs that influence an individual's behavior and environment, which in turn impact on health outcomes (Hu et al., 2010; Azar et al., 2017). The model involves major aspects of intervention which are planning, implementation and evaluation but this study focuses chiefly on the impact of health determinants and the evaluation of health outcomes. While the assessment of this study does not encompass all variables of the model, elements used are consistent with previous studies (Anderson et al., 2015; Azar et al., 2017). The precede-proceed model is used because it is an ecological model that offers a guide for evaluating health determinants and its impact on health outcomes. The model also acts as a tool for building, monitoring and adjusting interventions. (Green \& Kreuter, 2005).

Many works of literature support the flexibility and effectiveness of the precede-proceed model in evaluating programs and developing interventions for success (Anderson et al., 2015; Azar et al., 2017; Johnson, 2016; Moshki et al., 2016). In the study by Binkley and Johnson (2013), they tested the feasibility of the precede-proceed model in planning oral intervention strategy for adults with intellectual and development disabilities (IDD). Their study demonstrated that the model can be used for planning and developing strategies in dental care to improve oral health and quality of life. Li et al. (2009) suggested the need for focus programs on behavioral factors when they used the precede-proceed model to test for health needs assessment. They believe that the model provides an understanding of health problems confronting the communities of study, hence strategies for health promotion can be supplied. Johnson (2016) used the constructs of the model in a community-based physical activity and summer camp program for children. He evaluated the model and identified designated areas for improvement that will be established for future summer camp programs. His study reinforced the use of the precede-proceed model in program development and evaluation that promotes health outcomes. 


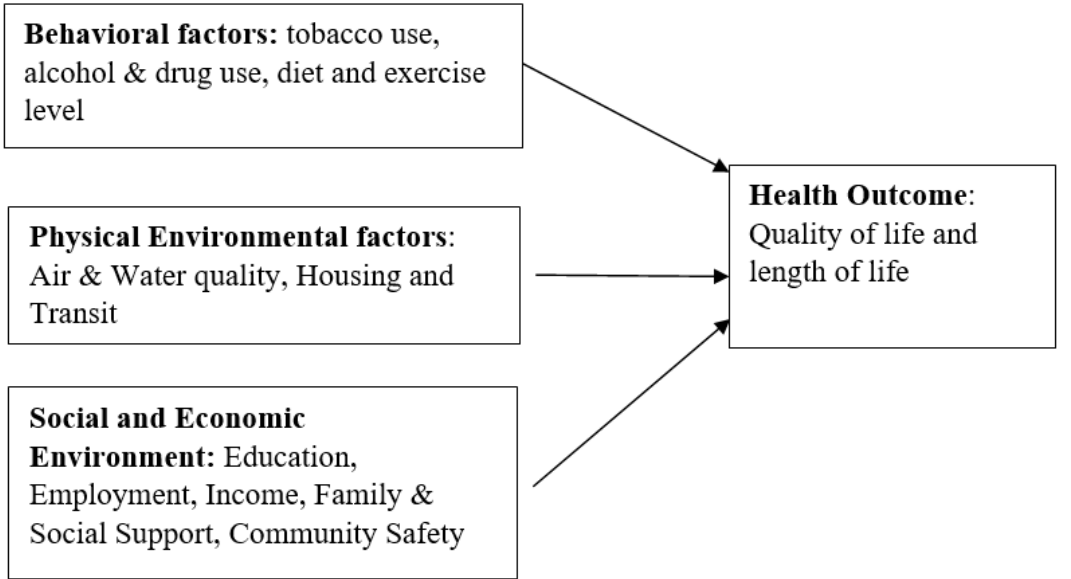

Figure 1: Health Outcomes Model (The above is derived from the precede-proceed model framework to explain the different relationship between variables being measured).

\subsection{Methodology}

Health outcome for Louisiana residents was measured with the behavior and environment diagnosis as seen in the precede-proceed model. Regression analyses were performed to identify which health determinants statistically influence health outcomes and the variation of the determinants in health outcomes over the years. The dependent variables were Quality of life and Length of life (health outcomes) while the independent variables were Health behavior, Social and economic environment and Physical environment.

Measure data for analyses were for all counties in Louisiana and they were from the County Health Rankings (CHR) starting from 2010 to 2019. For this study, we designate our variables based on County Health Rankings that measures length of life as premature death and quality of life as a measure of poor or fair health, poor physical health days, low mental health days and low birthweight (2019 County Health Rankings). The rankings also classify health behavior as a measure of tobacco, alcohol and drug use, adult obesity, and physical inactivity. Social and economic environments include unemployment, inadequate family and social support, low educational level, poverty and violence. Physical environment factors include air and water pollution, and housing and transit problems.

All statistical analyses were performed using SPSS and the significance level was set at $p<0.05$. Two regression models were constructed to identify possible determinants of health outcomes as follows:

Model 1: $\mathrm{QL}=f(\mathrm{HB}, \mathrm{SE}, \mathrm{PE})$, where $\mathrm{QL}=$ Quality of life, $\mathrm{HB}=$ Health behavior, $\mathrm{SE}=$ Social \& Economic Environment and $\mathrm{PE}=$ Physical Environment

$\mathrm{QL}=\alpha_{0}+\alpha_{1} H B+\alpha_{2} S E+\alpha_{3} P E+e_{i}$

$\mathrm{H}_{0}=$ length of life is not affected by health determinants

$\mathrm{H}_{1}=$ length of life is affected by health determinants

Model 2: $\mathrm{LF}=f(\mathrm{HB}, \mathrm{SE}, \mathrm{PE})$, where $\mathrm{LF}=$ Length of life, $\mathrm{HB}=$ Health behavior, $\mathrm{SE}=$ Social \& Economic Environment and $\mathrm{PE}=$ Physical Environment

$\mathrm{LF}=\alpha_{0}+\alpha_{1} H B+\alpha_{2} S E+\alpha_{3} P E+e_{i}$

$\mathrm{H}_{0}=$ quality of life is not affected by health determinants

$\mathrm{H}_{1}=$ quality of life is affected by health determinants 


\subsection{Results and Discussion}

Table 1: Output of Analysis Model 1: $Q L=f(H B, S E$, PE)

$\begin{array}{ll}\text { Health behavior } & 0.843^{* * *} \\ \text { Social and Economic Factors } & 1.088^{* * *} \\ \text { Physical Environment } & 1.956^{* * *} \\ \mathrm{R}^{2} & 83.50 \%\end{array}$

Dependent Variable: quality of life

Predictors: (Constant), $\mathrm{PE}=$ Physical Environment, $\mathrm{HE}=$ Health behavior, $\mathrm{SE}=$ Social and Economic Environment

\section{Model 2: $\mathrm{LF}=\boldsymbol{f}(\mathrm{HB}, \mathrm{SE}, \mathrm{PE})$}

$\begin{array}{ll}\text { Health behavior } & 0.59^{* * *} \\ \text { Social and Economic Factors } & 1.195^{* * *} \\ \text { Physical Environment } & -0.459 \\ \mathrm{R}^{2} & 57.30 \%\end{array}$

Dependent Variable: length of life

Predictors: (Constant), PE = Physical Environment, HE =Health behavior, $\mathrm{SE}=$ Social and Economic Environment

$* * * \mathrm{P}<0.01$

All three variables were consistently associated with health outcomes, quality of life and length of life for Louisiana residents. The relationship between the outcomes and independent variables was statistically significant at $p<0.01$. Table 1 shows the output from model 1 where quality of life is the dependent variable. The predicting power of the model shows that the three independent variables used in the study can explain the variation in quality of life up to $83.5 \%$ and each of the three variables were statistically significant at $p<0.01$. An increase in any of these variables will lead to an increase in poor health, poor physical and low mental health days. Table 1 also shows the relationship between dependent variable, length of life and the three independent variables from model 2. The model is statistically significant at $\mathrm{p}<0.01$. The independent variables explain a $57.3 \%$ variation in length of life. The variables, health behavior and social and economic environment are statistically significant at $p<0.01$, therefore an increase in these variables causes an increase in premature death. Physical environment in this model has a negative coefficient and it is expected that premature death reduces with an improved air and water quality or better housing and transit facilities. However, from our analysis, we do not have enough evidence to make this conclusion since physical environment is not significant in this model. For both models 1 and 2, we reject the null hypothesis since health behavior, social and economic environment, and physical environment impact health outcomes.

This result is consistent with other studies that have previously assessed the impact of the three determinants on health outcomes. Reports from World Health Organization (2005) established that these health determinants affect how people live and their risk of premature death. Thompson et al. (2012) examined factors affecting quality of life among older adults and he found smoking and low-level physical inactivity increase unhealthy days among the participants in their study. Raggi et al. (2016) addressed the determinants of quality of life in a cross-sectional study of three countries. They observed that putting an end to tobacco use, improving social network ties, increasing physical activity level and better housing or transport system potentially increase the quality of life. 


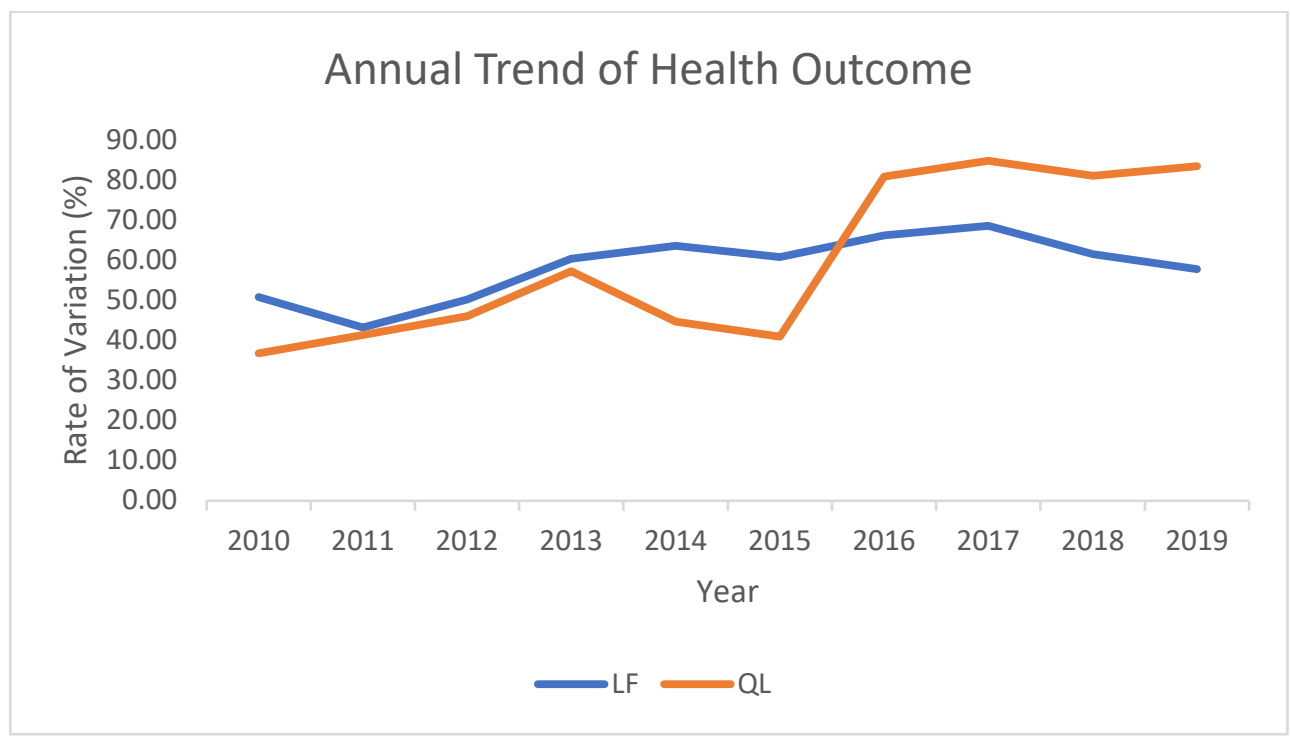

Figure 2: Annual Trend of Variation of Health Outcomes

Figure 2 shows the variation of health behavior, social and economic environment, and physical environment on the dependent variables, quality of life and length of life. In recent years (from 2015), the variations continue to rise in the quality of life. Unlike 2010 when the rate of variation was about $38 \%$, the rate of variation has reached approximately $84 \%$ in 2019 . This suggests that unhealthy health behaviors, undesirable social and economic lifestyle, and adverse physical environment is increasingly having significant impact on the quality of life of Louisiana population. Variation of the determinants in our study on length of life is not as high as in quality of life. From 2010 to 2019, the rate for length of life has varied between an approximate of 43 and 69 percent. However, over the last two years, there has been a decline from $69 \%$ in 2017 to $58 \%$ in 2019 .

\subsection{Conclusion and Recommendation}

In conclusion, building a bridge between the foundations of today and the systems of tomorrow is vital to maintaining population health at a lower cost. Our results show that the determinants of health in this study (health behavior, social and economic environment, and physical environment) have a significant influence on the health outcomes of Louisiana residents. These determinants have consistently, over the years impacted on the quality and length of life of the population, hence they are factors to consider when thinking of interventions. Intervening early in the life course of its residents, raising public awareness on factors that influence their health and providing assistance to accelerate change can help reduce these risk factors and make meaningful difference in improving health outcomes. Health providers, the Louisiana Department of Health (LDH), the government and policy makers need to see beyond the healthcare system to addressing factors and coordinating services that will improve health outcomes for its population.

\section{References}

Adler, N. E. \& Newman, K. (2002). Socioeconomic Disparities in Health: Pathways and Policies. Health Affairs 21(2). https://www.healthaffairs.org/doi/full/10.1377/hlthaff.21.2.60

Anderson, T. J., Saman D.M., Lipsky M.S. \& Lutfiyya M.N. (2015). A cross-sectional study on health differences between rural and non-rural U.S. counties using the County Health Rankings. BMC Health Services Research 5(1):441. doi.org/10.1186/s12913-015-1053-3

Armstrong, B. (1994). Getting health outcomes into state and national health policy, a national perspective. NSW Health Outcomes Conference, Sydney, 12-13 August 1994

Azar, F. E., Solhi, M., Nejhaddadgar, N. \& Amani, F. (2017). The effect of intervention using the PRECEDEPROCEED model based on quality of life in diabetic patients. Electronic Physician, 9(8), 5024-5030. doi:10.19082/5024

Baffour, T. D. (2017). Addressing the Social Determinants of Behavioral Health for Racial and Ethnic Minorities: Recommendations for Improving Rural Health Care Delivery and Workforce Development. Journal of Best Practices in Health Professions Diversity: Education, Research \& Policy, 10(2), 111-126.

Binkley, C. J., \& Johnson, K. W. (2013). Application of the PRECEDE-PROCEED Planning Model in Designing an Oral Health Strategy. Journal of theory and practice of dental public health, 1(3), Retrieved from http://www.sharmilachatterjee.com/ojs-2.3.8/index.php/JTPDPH/article/view/89.

County Health Rankings (2019). County Health Rankings and Roadmaps. Calculating scores and ranks. Available 
at http://www.countyhealthrankings.org/ranking-methods/calculating-scores-and-ranks

Elavsky, S., McAuley E., Motl R.W., Konopack J.F., Marquez D.X., Hu L., Jerome G. J \& Diener E. (2005). Physical activity enhances long-term quality of life in older adults: Efficacy, esteem, and affective influences. Annals of Behavioral Medicine 30(2) 138. https://doi.org/10.1207/s15324796abm3002_6

Green, L. W \& Kreuter, M. W. (2005). Health Promotion Planning: An Educational and Ecological Approach $4^{\text {th }}$ Edition. Mountain View, CA: Mayfield Publishers

Hu, J., Wallace, D. C., \& Tesh, A. S. (2010). Physical activity, obesity, nutritional health and quality of life in low-income Hispanic adults with diabetes. Journal of community health nursing, 27(2), 70-83. doi:10.1080/07370011003704933

Johnson, O. (2016). Application of the PRECEDE-PROCEED Model in the evaluation of a community-based youth fitness and nutrition summer camp program. Graduate College Dissertations and Theses. 647. https://scholarworks.uvm.edu/graddis/647

LaVeist, T. A., Gaskin D. J.\& Richard P. (2009). The Economic Burden of Health Inequalities in the United States. Joint Center for Political and Economic Studies. Retrieved from http://dph.illinois.gov/sites/default/files/publications/The_economic_burden_of_health_inequalities_US.pdf

Li, Y., Cao J., Lin H., Li D., Wang Y. \& He J. (2009). Community health needs assessment with precede-proceed model: a mixed methods study. BMC Health Serv Res 9, 181 doi:10.1186/1472-6963-9-181

McGraw-Hill Concise Dictionary of Modern Medicine. (2002). The McGraw-Hill Companies, Inc

McIlhenny, R. C. (2019). A Foolish Consistency: The Culture of Assessment in Higher Education. Confluence: The Journal of Graduate Liberal Studies, 25(1), 69-88.

Moshki, M., Dehnoalian A. \& Alami A. (2016). Effect of Precede-Proceed Model on Preventive Behaviors for Type 2 Diabetes Mellitus in High-Risk Individuals. Clin Nurs Res. January 2016:1-13. doi:10.1177/1054773815621026.

National Institutes of Health (2002). Strategic Research Plan and Budget to Reduce and Ultimately Eliminate Health Disparities Volume I Fiscal Years 2002-2006

Organization for Economic Co-operation and Development. (2016). "Tobacco and alcohol consumption", in Society at a Glance 2016: OECD Social Indicators, OECD Publishing, Paris. DOI: https://doi.org/10.1787/soc_glance-2016-25-en

Organization for Economic Co-operation and Development. (2019). Non-Medical Determinants of Health. OECD. Stat. Retrieved from https://stats.oecd.org/index.aspx?queryid=30127

Office of Disease Prevention and Health Promotion. (2017). Healthy People 2020 topics and objectives: Disability and health. Washington, DC: Office of Disease Prevention and Health Promotion. US Department of Health and Human Services. https:/www.healthypeople.gov/2020/topics-objectives/topic/disability-and-health

Orgera, K. \& Artiga, S. (2018). Disparities in Health and Health Care: Five Key Questions and Answers. Disparities Policy. Kaiser Family Foundation. Retrieved from https://www.kff.org/disparities-policy/issuebrief/disparities-in-health-and-health-care-five-key-questions-and-answers/\#footnote-267499-10

Raggi, A., Corso B., Minicuci N., Quintas R., Sattin D., De Torres L., Chatterji S., Frisoni G.B., Haro J.M., Koskinen S., Martinuzzi A., Miret M., Tobiasz-Adamczyk B. \& Leonardi M. (2016). Determinants of Quality of Life in Ageing Populations: Results from a Cross-Sectional Study in Finland, Poland and Spain. PLOS ONE 11(7): e0159293. https://doi.org/10.1371/journal.pone.0159293

Sansoni, J. (2016). Health Outcomes: An Overview from an Australian Perspective. Australian Health Outcomes Collaboration, Australian Health Services Research Institute, University of Wollongong, August.

Thompson, W. W., Zack M. M., Krahn G. L., Andresen E. M., \& Barile J. P. (2012). Health-related quality of life among older adults with and without functional limitations. American journal of public health, 102(3), 496502. doi:10.2105/AJPH.2011.300500

U.S. Department of Health and Human Services. (2008). The Secretary's Advisory Committee on National Health Promotion and Disease Prevention Objectives for 2020. Phase I report: Recommendations for the framework and format of Healthy People 2020 [Internet]. Section IV: Advisory Committee findings and recommendations. Available @ http://www.healthypeople.gov/sites/default/files/PhaseI_0.pdf.

U.S. Department of Health and Human Services. (2014). About Health Disparities. Retrieved from https://www.nhlbi.nih.gov/health/educational/healthdisp/about-health-disparities.htm

Wilkinson, R. \& Marmot, M. (2003). Social determinants of health: the solid facts. $2^{\text {nd }}$ Edition. CWorld Health Organization 2003

World Health Organization. (2005). The determinants of health. Available at https://www.who.int/hia/evidence/doh/en/ 


\begin{tabular}{|c|c|}
\hline \multicolumn{2}{|l|}{$\begin{array}{l}\text { Appendix } \\
\\
\text { Metadata }\end{array}$} \\
\hline \multicolumn{2}{|r|}{ HEALTH OUTCOMES } \\
\hline Focus Area & Measure \\
\hline Length of life & Premature death \\
\hline \multirow[t]{2}{*}{ Quality of life } & Poor physical health days \\
\hline & Low birthweight \\
\hline \multicolumn{2}{|r|}{ HEALTH BEHAVIORS } \\
\hline Focus Area & Measure \\
\hline Tobacco use & Adult smoking \\
\hline \multirow[t]{4}{*}{ Diet and exercise } & Adult obesity \\
\hline & Food environment index \\
\hline & Physical inactivity \\
\hline & Access to exercise opportunities \\
\hline \multirow[t]{2}{*}{ Alcohol and drug use } & Excessive drinking \\
\hline & Alcohol-impaired driving \\
\hline \multirow[t]{2}{*}{ Sexual activity } & Sexually transmitted infections \\
\hline & Teen births \\
\hline \multicolumn{2}{|r|}{ SOCIAL AND ECONOMIC ENVIRONMENT } \\
\hline Focus Area & Measure \\
\hline \multirow[t]{2}{*}{ Education } & High school graduation \\
\hline & Some College \\
\hline Employment & Unemployment \\
\hline \multirow[t]{2}{*}{ Income } & Children in poverty \\
\hline & Income inequality \\
\hline \multirow[t]{2}{*}{ Family and social support } & Children in single-parent households \\
\hline & Social associations \\
\hline \multirow{2}{*}{ Community Safety } & Violent crime \\
\hline & Injury deaths \\
\hline \multicolumn{2}{|r|}{ PHYSICAL ENVIRONMENT } \\
\hline Focus Area & Measure \\
\hline \multirow[t]{2}{*}{ Air and water quality } & Air pollution particulate matter \\
\hline & Drinking water violations \\
\hline \multirow[t]{3}{*}{ Housing and transit } & Severe housing problems \\
\hline & Driving alone to work \\
\hline & Long commute-driving alone \\
\hline
\end{tabular}

Source: County Health Rankings (2019). 